\title{
Noninvasively characterizing the different $\alpha v \beta 3$ expression patterns in lung cancers with RGD-USPIO using a clinical 3.0T MR scanner
}

This article was published in the following Dove Press journal:

International Journal of Nanomedicine

II November 2009

Number of times this article has been viewed

\section{Tao Jiangl,* \\ Chunfu Zhang ${ }^{2}$ \\ Xuan Zheng, ${ }^{3, *}$ \\ Xiongfei $\mathrm{Xu}^{4}$ \\ Xuan $\mathrm{Xie}^{2}$ \\ Hongchao Liu' \\ Shiyuan Liu'}

'Department of Radiology, ChangZheng Hospital Affiliated to Second Military Medical University, 4 I 5 Fengyang Road, Shanghai, China; 2Med-X Research Institute, Shanghai Jiao Tong University, Shanghai, China; ${ }^{3}$ Department of Nutrition, ChangHai Hospital Affiliated to Second Military Medical University, Shanghai, China; ${ }^{4}$ Department of Immunology, Second Military Medical University, Shanghai, China; *These authors contributed equally to this work
Correspondence: Prof. Shiyuan Liu Department of Radiology,

ChangZheng Hospital Affiliated to Second Military Medical University, 4 I5 Fengyang Rd, Shanghai, China

$\mathrm{Tel} / \mathrm{Fax}+862155232169$

Email laijiangtaotao@।39.com

Prof. Chunfu Zhang

Med-X Research Institute, Shanghai Jiao

Tong University, Shanghai 200030, China

$\mathrm{Tel} / \mathrm{Fax}+862162933323$

Email cfzhang@sjtu.edu.cn

\begin{abstract}
The adhesion molecule $\alpha \mathrm{v} \beta 3$ integrin plays an important role in tumor development and metastases. We demonstrated the specificity of the probe to $\alpha v \beta 3$ integrin with transmission electron microcopy (TEM) and magnetic resonance imaging (MRI). The in vivo targeting behavior of the probe was examined in 2 tumor models with different $\alpha v \beta 3$ expression patterns by a 3.0T MRI scanner. MR imaging showed that R2* pseudo-color pictures of A549 lung cancer tumor was different from that of 3LL lung cancer. For A549 tumor, an homogeneous decrease of signal intensity was observed throughout the tumor, which was more evident in the periphery or central areas. Histological studies revealed that $\alpha v \beta 3$ integrin was expressed both on the tumor vessel and tumor cells for A549 tumor. Our findings indicated that it was possible to noninvasively characterize the different $\alpha v \beta 3$ expression pattern in lung cancers with arginine-glycine-aspartic acid (RGD) peptide conjugated ultra-small superparamagnetic iron oxide nanoparticles (RGD-USPIO) using a clinical 3.0T MR scanner. Nevertheless, the way of imaging targeting presentation of the probe differed in tumors with different $\alpha v \beta 3$ expression patterns.
\end{abstract}

Keywords: USPIO, RGD peptide, $\alpha \mathrm{v} \beta 3$ integrin, MR molecular imaging

\section{Introduction}

Angiogenesis, as a fundamental step in the development, progression and metastasis of tumors, has become one of the most important and popular fields of tumor research in recent years, and a breakthrough is most likely in the future. ${ }^{1}$ Visual and quantitative studies of neovascularization are beneficial to early diagnosis of tumors and help whole-course monitoring of tumor neovascularization and evaluation of therapeutic effects during clinical use of angiogenesis antagonists for tumor treatment. ${ }^{2}$ Although many angiogenesis antagonists have been used in clinical trials, ${ }^{3}$ we are convinced that the success of this therapeutic approach is bound to be accompanied by the development of a highly specific marker for angiogenesis and effective imaging techniques to determine the optimal therapeutic dosage at morphological, functional and molecular levels and monitor patient's therapeutic responses. ${ }^{4}$ We are sure that the study of angiogenesis imaging will play an important role in tumor early diagnosis and wholecourse monitoring of response to antitumor angiogenesis therapy.

Integrin is a superfamily of adhesion molecules and plays an important role in tumor angiogenesis and metastasis. ${ }^{5}$ Integrin $\alpha v \beta 3$ can bind with arginine-glycine-aspartic acid (RGD) in an extracellular matrix (ECM). It is expressed at high density in activated tumor vessels and at low density in rest-stage endothelial cells. ${ }^{6}$ Although an RGD polypeptide target-labeled $\alpha v \beta 3$ diagnostic probe has been developed and used in

submit your manuscript | www.dovepress.con 
positron emission tomography (PET) ${ }^{4}$ single photon emission computed tomography (SPECT), optical imaging ${ }^{7}$ and ultrasound imaging, ${ }^{8}$ and the radioactive tracer ${ }^{18} \mathrm{~F}-\mathrm{FDG}-\mathrm{RGD}$ target-labeled $\alpha v \beta 3$ has been used in PET for human trials, ${ }^{9}$ one of the inadequacies of PET monitoring is its low spatial resolution. ${ }^{4}$ In contrast, magnetic resonance imaging (MRI) not only has a higher spatial resolution but also provides better contrast for the soft tissues without ionizing radiation. Therefore, good prospects are expected in target imaging of angiogenesis. ${ }^{10}$ The inadequacy of MRI is its low sensitivity. Ultra-small superparamagnetic iron oxide (USPIO) is a new MRI contrast medium, mainly producing T2 negative contrast effect. As its unit iron can produce more signal changes, USPIO overcomes the disadvantage of the low sensitivity of conventional MRI contrast media. Zhang, a member of our research team, has developed a USPIO probe and coupled it with RGD to target and label $\alpha v \beta 3$ receptor molecules specifically expressed in endothelial cells of tumor angiogenic blood vessels. The results showed that it was possible to identify the nature of a tumor by the degree of $\alpha v \beta 3$ expression and the profile of tumor angiogenic blood vessels, thus making trace tumor angiogenesis much easier. In addition, it was helpful in judging the prognosis of the tumor detected..$^{11}$ Unfortunately, Zhang's USPIO probe was tried only on $1.5 \mathrm{~T}$ MR imaging in vivo in a tumor model with negative $\alpha v \beta 3$ expression. Now 3.0T MR has been used widely in clinical practices. In addition, the development of coils for small animals has greatly raised the signal-to-noise ratio of images, which helps identify micro-lesions much more clearly. It is also known that $\alpha v \beta 3$ expression occurs not only on angiogenic blood vessels but on the surface of tumor cells. ${ }^{7}$ However, it is unclear whether a tumor model with positive $\alpha v \beta 3$ expression would affect the targeting of the probe.

The purpose of the present study was to use 3-aminopropyltrimethoxysilane (APTMS)-coated USPIO coupled with an integrin targeted RGD polypeptide to develop a nanoprobe that can bind with integrin $\alpha v \beta 3$, and then to test it with a clinical 3.0T MR scanner in animal lung cancer models in vivo to see whether it can maintain its targeting in tumors with different $\alpha v \beta 3$ expression patterns, and differentiate quantitatively the cumulative effects of the probe by $\mathrm{T} 2$ relaxation rate.

\section{Materials and methods}

\section{Preparation of RGD-USPIO nanoprobe "I}

All chemical materials were purchased from Sinopharm Chemical Reagent Co., Ltd. $c$ (RGDfK) was purchased from Peptides International, Inc. (Louisville, KY, USA).

\section{Preparation and decoration of magnetic nanoparticles}

Magnetic nanoparticles were prepared by a chemical coprecipitation method. ${ }^{12}$ Appropriate amounts of $\mathrm{FeSO}_{4}$ and $\mathrm{FeCl}_{3}$ were mixed at a 1:2 molar ratio and transferred to a 3-necked flask, to which an excess amount of $\mathrm{NaOH}$ solution was added gradually with mechanical agitation. The reaction was maintained at $60^{\circ} \mathrm{C}$ for 1 hour to obtain $\mathrm{Fe}_{3} \mathrm{O}_{4}$ nanoparticles. After washing with deionized water and ethanol 3 times in sequence, the particles were combined with (3-aminopropyl)trimethoxysilane $\left(\mathrm{Si}\left(\mathrm{OC}_{2} \mathrm{H}_{5}\right)_{3} \mathrm{C}_{3} \mathrm{H}_{7} \mathrm{NH}_{2}\right.$, APTMS), reacted at $70{ }^{\circ} \mathrm{C}$ for 4 hours, and finally washed with de-ionized water to obtain magnetic particles with an amino group on the surface.

\section{Coupling of RGD polypeptide}

Glutaraldehyde phosphate-buffered saline (PBS) (pH 7.4) solution (v/v, 5\%) was prepared. $50 \mathrm{mg}$ APTMS-coated magnetic particles were diffused in $2 \mathrm{~mL}$ glutaraldehyde solution and agitated at room temperature for 4 hours. Glutaraldehydeactivated magnetic particles were retrieved with a magnet and washed with PBS 3 times. $0.5 \mathrm{mg}$ RGD polypeptide was dissolved in $0.5 \mathrm{~mL}$ PBS ( $\mathrm{pH} 7.4$ ). $10 \mathrm{mg}$ activated magnetic particles were diffused in polypeptide solution and oscillated for 24 hours. The polypeptide-coupled magnetic microparticles were collected with a magnet, washed with PBS 3 times, diffused in $1 \mathrm{~mL} 1 \mathrm{~mol} / \mathrm{L}$ glycine solution, and sealed for 1 hour. The as-prepared probe was precipitated, washed and finally dispersed into PBS ( $\mathrm{pH} 7.4)$ solution.

\section{In vitro evaluation of specificity of the RGD-USPIO probe} Relaxometry and MR imaging of labeled HUVECs

Cell culture

Human umbilical vein endothelial cells (HUVECs) with positive $\alpha v \beta 3$ receptor expression (Biosis Biotechnology Co., Ltd., Shanghai, China) were maintained with endothelial cell culture medium (199 culture solution) supplemented with $10 \%$ fetal bovine serum, $100 \mathrm{IU} / \mathrm{mL}$ penicillin and $100 \mu \mathrm{g} / \mathrm{mL}$ streptomycin under $5 \% \mathrm{CO}_{2}$ atmosphere at $37^{\circ} \mathrm{C}$.

HUVECs were incubated with the RGD-USPIO or plain USPIO at an iron concentration of $0.03 \mu \mathrm{mol} / \mathrm{mL}$ for different periods of time (10 $\mathrm{min}, 30 \mathrm{~min})$. After incubation, the culture medium was removed and the cells were washed with PBS (0.1 mol/L, pH 7.4) 3 times, trypsinized and suspended in culture medium. Cells were retrieved by centrifugation at $2000 \mathrm{~g}$ for $5 \mathrm{~min}$. For relaxometry and MR imaging, cells $\left(2 \times 10^{6}\right)$ were embedded in $400 \mu \mathrm{L} 10 \%$ gel. MR imaging 
was performed with a 3.0T MR scanner (GE SIGNA EXITE II) equipped with a mouse-imaging coil for signal excitation and reception with the following sequences:

T2 weighted FRFSE-XL sequence for morphology: $\mathrm{TR}=3960 \mathrm{~ms}$; TE $=105.2 \mathrm{~ms}$; wave width $19.2 \mathrm{kHz}$; FOV $=10 \mathrm{~cm}$; matrix $=256 \times 192 ;$ thickness $/$ interval 2.0/0.5 mm; 4 collections).

T2* weighted gradient echo sequence for calculation of $\mathrm{T}^{*}$ and $\mathrm{R} 2 *$ value: $\mathrm{TR}=120 \mathrm{~ms}$; $\mathrm{TE}=2.6-41.6 \mathrm{~ms}$; wave width $=31.3 \mathrm{kHz} ;$ FOV $=8 \mathrm{~cm}$; matrix $=288 \times 192$; thickness/interval $2.0 / 0.5 \mathrm{~mm} ; 4$ collections.

$\mathrm{T} 2 *$ and $\mathrm{R} 2 *$ values were automatically calculated by GE functional tool software package (ADW4.2 work platform). The mean value was obtained from calculations of 3 zones.

\section{TEM Study of HUVECs}

For TEM study of cells, cells were incubated with the RGD-USPIO or plain USPIO at an iron concentration of $0.03 \mu \mathrm{mol} / \mathrm{mL}$ for $10 \mathrm{~min}$ or $30 \mathrm{~min}$. After incubation, cells were washed with PBS (0.1 mol/L, pH 7.4) 3 times, trypsinized and retrieved by centrifugation. Then cells were fixed with $2.5 \%$ glutaraldehyde at $4{ }^{\circ} \mathrm{C}$ overnight, stained with $2 \%$ osmic acid and $0.5 \%$ uranyl acetate, and sliced into $5 \mu \mathrm{m}$ sections. Micrographs were taken with a HITACHI H800 electron microscope at $100 \mathrm{kV}$. The magnification indicator was routinely controlled by the use of a grating replica.

\section{MRI detecting $\alpha v \beta 3$ integrin in vivo}

All procedures were approved by the animal center of the Second Military Medical University (Shanghai, China). For detecting $\alpha v \beta 3$ integrin in vivo, tumor xenograft with nonsmall cell lung cancer cells ( 3 LL or A549, $5 \times 10^{5}$ cells, Biosis Biotechnology Co., Ltd Shanghai, China) were implanted into the left armpit of $\mathrm{Bal} / \mathrm{C}$ mice. When tumors reached $1 \mathrm{~cm}$, the RGD-USPIO or plain USPIO were used to inject the mice (six 3LL mice and five A549 mice respectively) at a dose of $100 \mu \mathrm{mol} \mathrm{Fe} / \mathrm{kg}$ through the tail vein. After injection, MR imaging was performed with a 3.0T MR scanner (GE SIGNA EXITE II) with the following sequences:

T2 weighted FRFSE-XL sequence for morphology: $\mathrm{TR}=3960 \mathrm{~ms} ; \mathrm{TE}=105.2 \mathrm{~ms}$; wave width $=19.2 \mathrm{kHz}$; $\mathrm{FOV}=10 \mathrm{~cm}$; matrix $=256 \times 192 ;$ thickness $/$ interval 2.0/0.5 mm; 4 collections.

T2* weighted gradient echo sequence for calculation of $\mathrm{T} 2 *$ value and $\mathrm{R} 2 *$ value: $\mathrm{TR}=120 \mathrm{~ms}$; $\mathrm{TE}=2.6-41.6 \mathrm{~ms}$; wave width $=31.3 \mathrm{kHz} ; \mathrm{FOV}=8 \mathrm{~cm}$; matrix $=288 \times 192$; thickness/interval 2.0/0.5 mm; 4 collections.
$\mathrm{T} 2 *$ and R2* values of the tumor, blood, liver, kidney, heart and muscle before and after probe injection were automatically calculated by GE functional tool software package (ADW4.2 work platform). Pseudo-olor images of MR R2* values also were delineated by the same software. The mean value was obtained from calculations of 3 zones.

\section{Hematoxylin and eosin (HE) stain and immunohistochemistry} Streptavidin-perosidase (SP) staining of tumor cells Cells were plated in 6-chamber plates (Biosis Biotechnology Co., Ltd., Shanghai, China) at a concentration of $2 \times 10^{4}$ cells/ well. When cell growth was $80 \%$ confluent, the cell was fixed with paraformaldehyde (v/v, 4\%). For SP staining, 3LL or A549 lung cancer cell (murine cells) was first incubated with hamster antimouse CD61 ( $\beta 3$ ) primary antibody (1:100 dilution) at $4{ }^{\circ} \mathrm{C}$ overnight, then with biotin-labeled antihamster secondary antibody (1:100 dilution) at room temperature for $30 \mathrm{~min}$. After washing with PBS 3 times, $100 \mu \mathrm{L}$ (1:200 dilution) streptavidin-coupled horseradish peroxidase (streptavidin-HRP) was added and incubated at room temperature for $20 \mathrm{~min}$, followed by adding freshly prepared $0.01 \%$ diaminobenzidine with 5-10 min incubation. The reaction was terminated by washing with distilled water 3 times. Cells were counterstained with hematoxylin-esoin and returned to blue with ammonia water. After drying with gradient alcohol and xylene, cells were mounted with $50 \%$ glycerine.

\section{$\mathrm{HE}$, SP staining of tumor tissues}

After MR imaging, the mouse were sacrificed and the subcutaneous tumor tissue was removed completely and fixed with glutaraldehyde at $4{ }^{\circ} \mathrm{C}$ overnight, paraffin-embedded, and sliced into $4 \mu \mathrm{m}$ sections.

For HE staining, the sections were dewaxed with xylene and washed with ethanol and water successively. After hematoxylin staining for $5 \mathrm{~min}$, the sections were washed with distilled water, differentiated with ethanol for $30 \mathrm{sec}$ and soaked for $5 \mathrm{~min}$ in $50^{\circ} \mathrm{C}$ water, followed by conterstaining with eosin solution for $2 \mathrm{~min}$.

For SP staining, the sections were heated in a microwave oven to maintain the temperature at $92-98^{\circ} \mathrm{C}$ for $10-15 \mathrm{~min}$ for antigen retrieval, then incubated with $10 \%$ normal goat serum. For tumor tissue SP staining, the procedure was the same as that for tumor cell SP staining described above. After staining, the sections were dehydrated with gradient ethanol, hyalinized with xylene, then mounted on the slip. 


\section{Statistical analysis}

The Wilcoxon rank sum test was used for statistical evaluation. $P<0.05$ was considered statistically significant.

\section{Results}

\section{Charactierization of RGD-USPIO probe}

TEM examination indicated that the size of nano- $\mathrm{Fe}_{3} \mathrm{O}_{4}$ particles was $10 \pm 2 \mathrm{~nm}$, and did not undergo significant change after modification (Figure 1). The coating was manifested by inductively coupled mass spectrometry; iron and silicon contents were $68.83 \mathrm{wt} \%$ and $1.316 \mathrm{wt} \%$, respectively. Organic element analysis further indicated that the contents of carbon, hydrogen and nitrogen were $3.56 \mathrm{wt} \%, 1.22 \mathrm{wt} \%$ and $1.50 \mathrm{wt} \%$, respectively. $\mathrm{T} 2$ and $\mathrm{T} 1$ relaxivity values of RGD-UAPIO were 114.9 and $10.64 \mathrm{~s}^{-1}$ $(\mathrm{mmol} / \mathrm{L})^{-1}$.

\section{Specificity study of RGD-USPIO probe in vitro}

The specificity of the RGD-USPIO probe for $\alpha v \beta 3$ integrin was examined by relaxometry measurement and MR imaging of HUVECs cells (Figure 2). The T2* value of cells was $193.22 \pm 10.71 \mathrm{~ms}$ after incubation with the RGD-USPIO probe at an iron concentration of $0.03 \mu \mathrm{mol} / \mathrm{mL}$ for $10 \mathrm{~min}$, which decreased to $182.58 \pm 8.94 \mathrm{~ms}$ after $30 \mathrm{~min}$ incubation. For the control cells (cells incubated with plain USPIO with

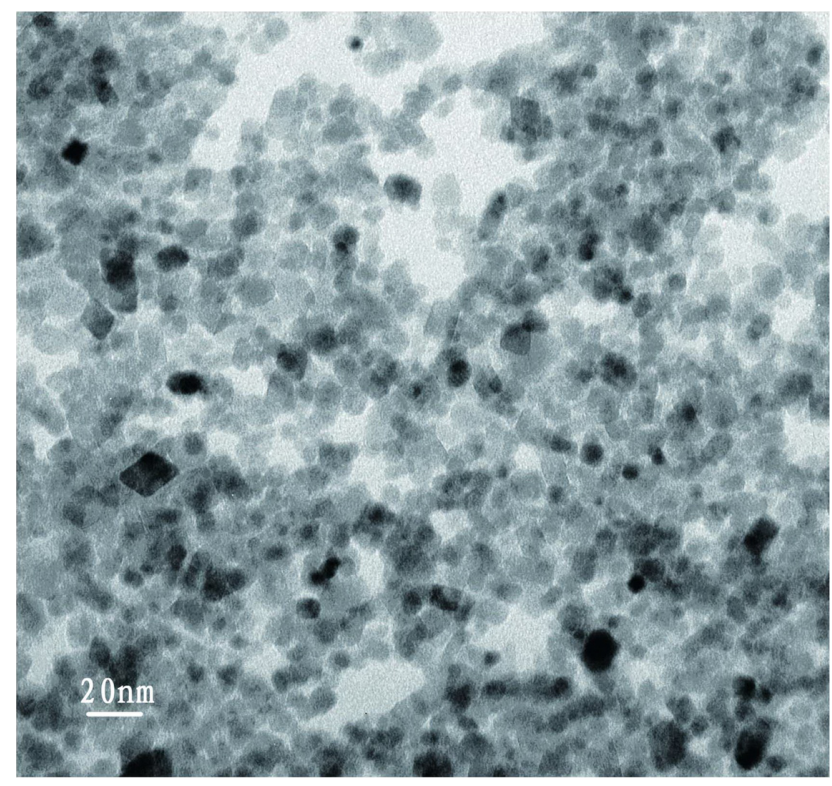

Figure I Transmission electron microscopy (TEM) picture of RGD-USPIO nanoparticles. TEM examination indicated that the size of RGD-USPIO particles was $10 \pm 2 \mathrm{~nm}$. Abbreviations: RGD-USPIO, arginine-glycine-aspartic acid peptide conjugated ultrasmall superparamagnetic iron oxide nanoparticles (RGD-USPIO). the same iron concentration), the $\mathrm{T} 2 *$ value was $206.64 \pm 9.69$ $\mathrm{ms}$, even after incubation for $30 \mathrm{~min}$, significantly different from the decrease in the $\mathrm{T} 2 *$ with the RGD-USPIO probe $(P<0.05)$.

Consistent with relaxometry measurement, co-culture of HUVECs with plain USPIO or RGD-USPIO both reduced signal intensity (Figure 2B). However, compared with the control cells, after incubation for $10 \mathrm{~min}$ the decrease in signal intensity for cells incubated with RGD-USPIO was heterogeneous and much more pronounced. After $30 \mathrm{~min}$ co-culture with RGD-USPIO, the reduction in signal intensity was even more evident.

TEM images of cells co-cultured with RGD-USPIO or plain USPIO are shown in Figure 3, which shows that a certain amount of the RGD-USPIO probe was already internalized by endothelial cells after $10 \mathrm{~min}$ co-culture, and even more RGD-USPIO after 30 min co-culture. In the control group, the plain USPIO probe was mainly distributed outside endothelial cells, with only a small number of particles being attached to the cell membrane.

\section{In vivo imaging of $\alpha v \beta 3$ expression}

SP staining indicated the different expression patterns of $\alpha v \beta 3$ integrin in A549 and 3LL tumor cells (Figure 4). For the A549 cell line, $\alpha v \beta 3$ integrin was expressed mainly on the cell membrane and partially on endochylema. For $3 \mathrm{LL}$ cells, no $\alpha \mathrm{v} \beta 3$ expression was found.

T2*-weighted MR images showed that after the administration of the RGD-USPIO probe, the reduction

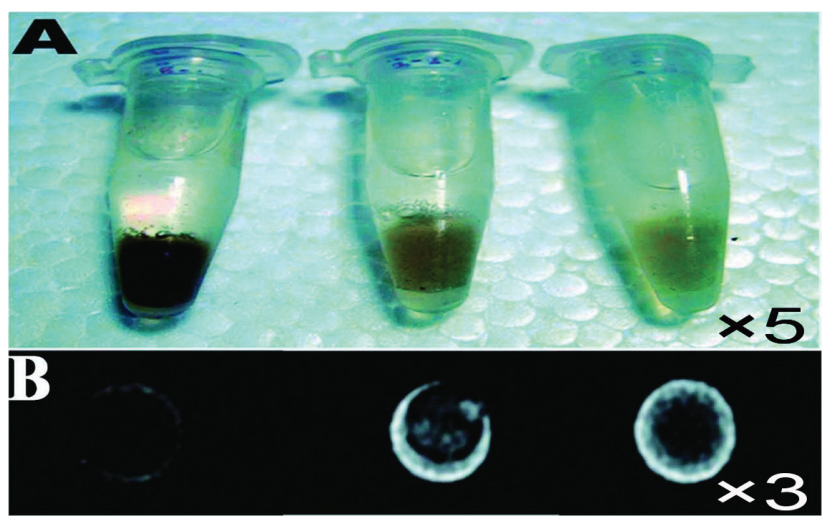

Figure 2 Cell suspended in gel $\mathbf{A}$ ) and magnetic resonance imaging of the cells B) after co-cultured with RGD-USPIO for $30 \mathrm{~min}$ (left) and $10 \mathrm{~min}$ (middle) or plain USPIO (right) for $30 \mathrm{~min}$. Compared with control, more RGD-USPIO was internalized by HUVECs, leading to a darker color and pronounced MRI signal intensity decrease of cells incubated with RGD-USPIO. Moreover, cell uptake of RGD-USPIO increased with increase of incubation time.

Abbreviations: HUVECS, human umbilical vein endothelial cells; RGD-USPIO, arginine-glycine-aspartic acid peptide conjugated ultra-small superparamagnetic iron oxide nanoparticles (RGD-USPIO). 

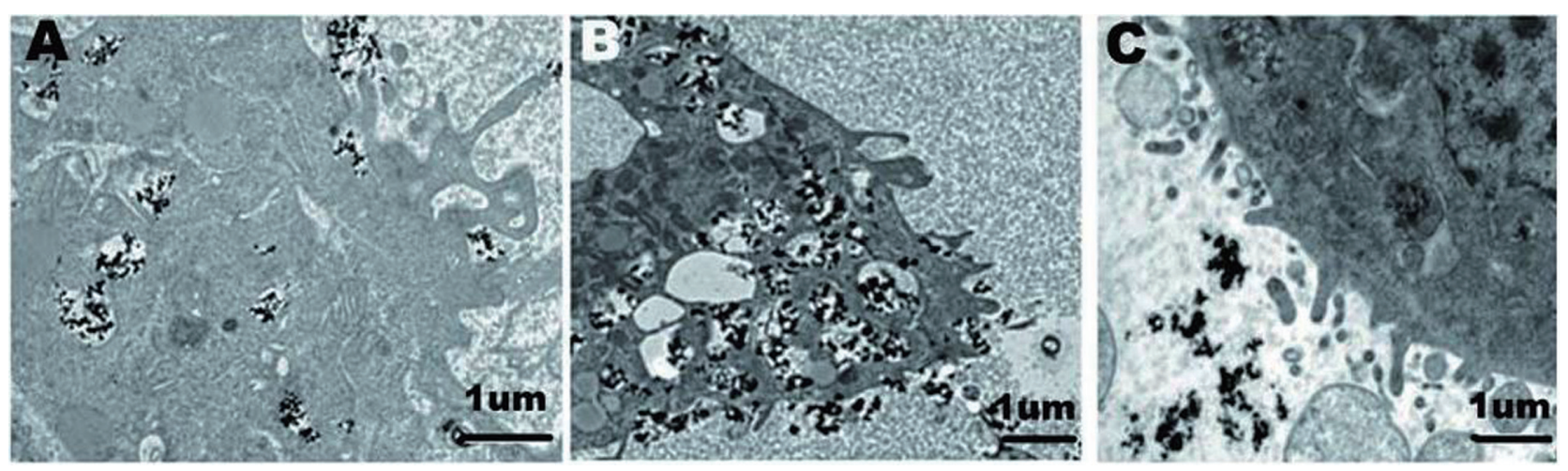

Figure 3 Transmission electron microscopy images of HUVECs co-cultured with RGD-USPIO for 10 min A) and 30 min B) or USPIO for 30 min C) at the iron concentration of $0.03 \mu \mathrm{mol} / \mathrm{mL}$. A certain amount of RGD-USPIO probe was ready internalized by the cells 10 min after co-culture and even more after 30 min co-culture. In contrast, the plain USPIO probe was distributed mainly outside endothelial cells, with only a small number of particles attached to the cell membrane.

Abbreviations: HUVECS, human umbilical vein endothelial cells; RGD-USPIO, arginine-glycine-aspartic acid peptide conjugated ultra-small superparamagnetic iron oxide nanoparticles (RGD-USPIO).

of signal intensity in 3LL tumor was distributed mainly in the periphery and some central areas of the tumor. This observation was more vividly reflected by pseudocolor images of MR R2* values: the intense orange surrounding the tumor indicates the increase of $\mathrm{R} 2 *$ value on the periphery of the tumor, corresponding to the decrease of signal intensity. In contrast, signal reduction was not significantly different on both MR images of the tumor after administration of plain USPIO (Figure 5). Consistent with MR imaging, the difference in $\mathrm{R} 2 *$ value of tumors after and before injection of the RGD-USPIO probe was $84.16 \pm 13.00 \mathrm{~s}^{-1}$, compared with $18.82 \pm$ $4.42 \mathrm{~s}^{-1}(P<0.05)$ for tumors receiving plain USPIO (Figure 6). Microscopically, the angiogenic blood vessels were displayed mainly in the periphery and some central areas of $3 \mathrm{LL}$ tumor, and SP staining showed that the neoveculature was $\alpha v \beta 3$ positive (Figure 4).

In contrast to $3 \mathrm{LL}$ tumor, reduction of signal intensity in $\mathrm{T} 2 *$-weighted images after the administration of the RGD-USPIO probe in the A549 tumor model was homogeneous and a reduced signal intensity was observed in the periphery of and inside the tumor. Moreover, the area of increased $\mathrm{R} 2 *$ value reflected by pseudo-color pictures was seen throughout the tumor and was more evident in the periphery or central areas. After plain USPIO injection, no significant signal reduction could be found (Figure 5). R2* value increased significantly after injection of the RGD-USPIO probe $\left(101.74 \pm 6.27 \mathrm{~s}^{-1}\right)$ compared with that of the plain USPIO group $\left(24.46 \pm 4.45 \mathrm{~s}^{-1}\right)(P<0.05)$ (Figure 6). For histological study, HE staining was similar to that of 3LL lung cancer, and the angiogenic blood vessels were seen mainly in the periphery of the tumor.
However, both vascular endothelial and tumor cells were $\alpha v \beta 3$ integrin positive (Figure 4).

The injection of the RGD-USPIO also induced the reduction of $\mathrm{T}^{*}$ value of other organs, such as liver, kidney and muscle, most significantly in the liver (Figure 6).

\section{Discussion}

Although clinically available MR contrast media and various probes for detecting angiogenesis are able to enhance T1 positive signals, ${ }^{13-15}$ negative contrast is still comparatively advantageous because USPIO produces a reduction effect of T2 relaxation time, which can be enhanced by the magnetic-sensitive effect of gradient echo sequence, thus producing excess voxel and enhancing MR sensitivity at the same time. ${ }^{16}$ It has been documented that this magneticsensitive effect is more evident in 3.0T magnetic field than in 1.5 T magnetic field. ${ }^{17}$

The present study attempts to evaluate the expression of $\alpha v \beta 3$ integrin in different lung cancer models in vivo by observing binding of the RGD-USPIO probe with $\alpha v \beta 3$ with a 3.0T MR scanner by using APTMS-coated USPIO coupling with RGD polypeptide. The merit of coating the probe with ATPMS is that in addition to the amino groups being exposed on the surface of the particles, and thus able to couple with specific ligands covalently, the coating layer can be made very thin without inducing any MR signal loss under the encapsulation. ${ }^{18}$ This is important to maintain the nano-class diameter of the particles. Generally, the smaller the diameter of the probe, the better the pharmacokinetics. In addition, such a probe usually has better extravasation and binding ability with the target after coupling with specific ligands. ${ }^{19,20}$ The RGD polypeptide 

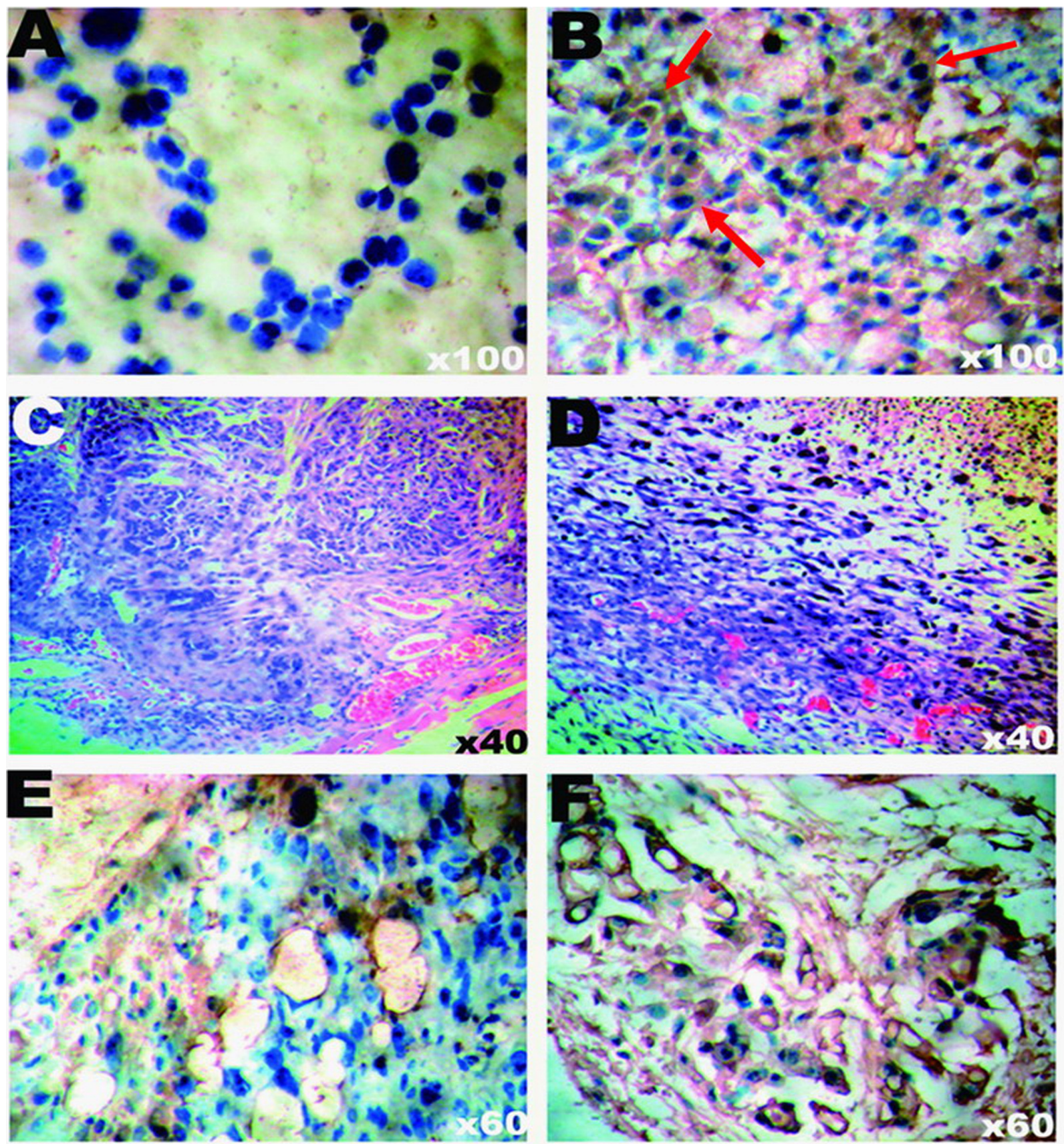

Figure $4 \mathrm{HE}$ and SP staining of tumor cells $(\mathbf{A}, \mathbf{B})$ or tumor tissues (C-F). The different expression patterns of $\alpha \mathrm{v} \beta 3$ integrin were shown by SP staining. For $3 \mathrm{LL}$ cells, there was no $\alpha v \beta 3$ expression found A). For A549 cell line, $\alpha v \beta 3$ integrin was expressed mainly on the cell membrane and partially on endochylema (B arrow), Microscopically, the newborn vessels were displayed mainly in the periphery and some central areas of $3 \mathrm{LL}$ tumor in $\mathrm{HE}$ staining $\mathbf{C}$ ), and SP staining showed that the neoveculature was $\alpha v \beta 3$ positive E). For A549 histological study, HE staining was similar to that of $3 \mathrm{LL}$ lung cancer and the newborn vessels were seen mainly in the periphery of the tumor D). Both vascular endothelial and tumor cells were $\alpha v \beta 3$ expression positive $\mathbf{F}$ ). There was no apparent difference in distribution of newborn vessels and necrosis in the pathological sections.

Abbreviations: $\mathrm{HE}$, hematoxylin and eosin; SP, streptavidin-peroxidase.

used in the present study is a commercial available cyclo RGD ( $c$ (RGDfK)), whose stability is 30 times more than that of linear RGD. ${ }^{21}$ Zhang et al has used a similar method to perform MRI. The results showed that it was possible to identify the nature of the tumor through the degree of $\alpha v \beta 3$ expression and the profile of tumor angiogenic blood vessels, thus making tracing of tumor angiogenesis much easier. ${ }^{11}$

However, we cannot exclude the possibility of some RGD peptides coupling with the activated USPIO through the amino group of arginine in RGD peptide at the active binding sites, which may impair specificity of the probe. For this 

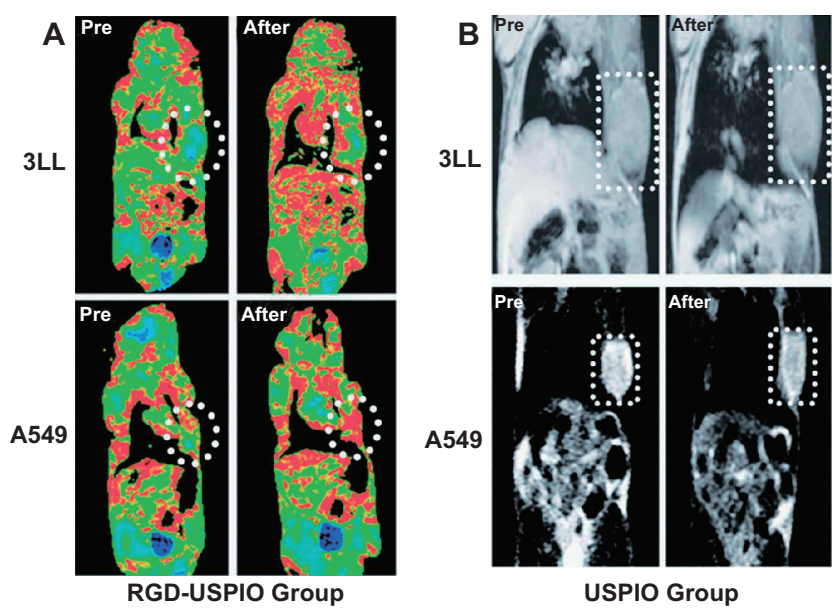

Figure 5 Pseudo-color magnetic resonance (MR) images of tumors after the injection of RGD-USPIO A) and T2-weighted MR images of tumor after the injection of USPIO B) Pseudo color MR images reflected the reduction of signal intensity in $3 \mathrm{LL}$ tumor mainly distributed in the periphery and some central areas of the tumor after the administration of RGD-USPIO probe. Different from 3LL tumor, for A549 tumor, the area of increased R2* value was seen throughout the tumor and more evident in the periphery or central areas $\mathbf{A}$ ). In contrast, signal reduction was not significantly different after administration of plain USPIO on both MR images of $3 \mathrm{LL}$ and A549 tumor B).

Abbreviation: RGD-USPIO, arginine-glycine-aspartic acid peptide conjugated ultrasmall superparamagnetic iron oxide nanoparticles (RGD-USPIO).

reason, we conducted the in vitro experiment and found that the RGD-USPIO was able to bind to HUVECs specifically, and that this binding ability was receptor-mediated (cell) endocytosis. MR examination of the cell gel suspension showed that the MR signal intensity decrease of HUVECs co-cultured with the RGD-coupled USPIO probe was much more significant than that of HUVECs incubated with the plain USPIO probe, confirming the unimpaired specificity of the RGD-USPIO probe.

We also observed characteristic MR signal changes of $\alpha v \beta 3$ expression in different tumor models on T2* and R2* pseudo-color pictures after RGD-USPIO injection in mice, and differentiated the accumulative effect of the probe by $\mathrm{T} 2 *$ quantification. It was found that RGD-USPIO caused heterogeneous signal reduction in 3LL lung cancer mice mainly in the periphery and a few central areas of the tumor, which is consistent with the type of tumor angiogenesis and the pattern of integrin expression confirmed by the histological study of the tumor tissue. This also agrees with previous findings in $\alpha v \beta 3$-negative tumors. ${ }^{11}$ In tumor-bearing mice injected with USPIO alone, there was only a slight change in background signals on MR images, probably due to extravasation of particles from tumor vessels and dissemination to intercellular space. ${ }^{22}$

However, we found that the probe distribution pattern on T2*-weighted MR imaging of A549 lung cancer mice with positive $\alpha v \beta 3$ expression on tumor cells was different from that in 3LL lung cancer mice with negative $\alpha v \beta 3$ expression on tumor cells. For A549 tumors, low signal areas were in both the periphery of and inside the tumor, but more prominent in the periphery. $\mathrm{T} 2$ relaxation times of the two tumors were significantly lower than that of the USPIO control group, though the difference between these tumors was not statistically significant. We first exclude the possibility of heterogeneity of angiogenesis due to different sizes of the two tumors, because there is no significant difference in the microvessel density between tumors with a size of $1 \mathrm{~cm} .{ }^{23}$ Thus, the possibility that the differences might be related to the tumor development of the necrosis areas is also excluded. It is true that a tumor with a size of $1 \mathrm{~cm}$ might have necrosis, but there was no apparent difference between the two type of lung cancer in the pathological sections. The possible explanation is that this difference is related to $\alpha v \beta 3$ expression. Immunohistochemistry showed that for the A549 tumor, CD61 is not only expressed in angiogenic blood tumor vessels but also in tumor cells around the vessels. Therefore, it is reasonable to speculate that part of the RGD-USPIO probes extravasate from tumor vessels and bind with tumor cells due to the loose connection between endothelial cells of angiogenic blood vessels. ${ }^{24}$ So, this different enhancement pattern in MR imaging of different tumor may not only be related to the profile of tumor angiogenic blood vessels, but may also involve specific binding between the RGD-USPIO and tumor cells. ${ }^{25}$ Thus, tumor cells would interfere with the targeting of the probe to angiogenic blood vessels. This will make it difficult to evaluate in vivo angiogenesis of tumors with positive $\alpha v \beta 3$ expression and to detect the effects of antiangiogenesis therapies. Indeed, this question cannot be answered by the preliminary results obtained in a small number of animals in the present study. Especially, the in vivo experiments are challenging because the RGD-USPIO cannot reach tumor cells easily (due to their short circulation time). In addition, evaluation of MR targeting in vivo cannot not be as accurate as immunohistochemical staining of tumor tissue, because the marker is less sensitive. Another reason is that various conditions in vivo (such as water buffering or plasma buffering) may affect detection of the relaxation rate, causing overestimation of local concentrations in vivo. ${ }^{26}$

Whether the contrast medium could be transported to the target is also a difficult problem due to nonspecific phagocytosis of macrophages..$^{27}$ Most probes are absorbed by the liver and reticular endothelial system, whose uptake may even exceed that in tumor areas, which makes it difficult to 

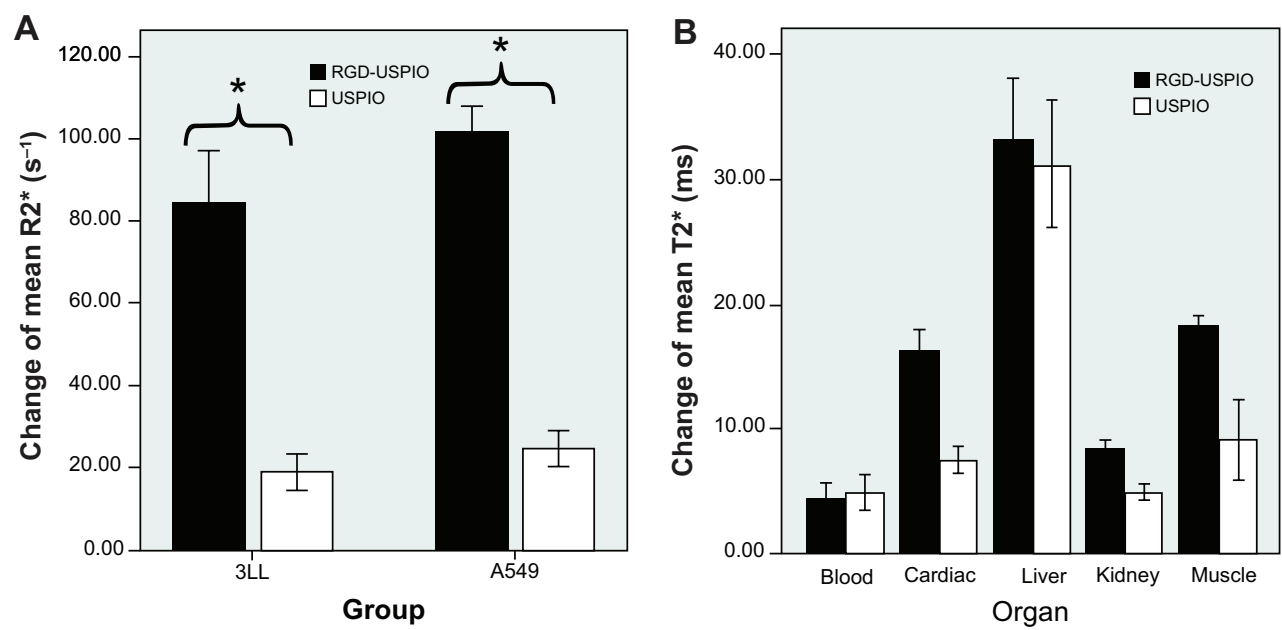

Figure 6 Change in R2* value of tumors A) and T2* value of organs B) after administration of RGD-USPIO or plain USPIO. The difference in R2* value of 3 LL tumor before and after injection of the RGD-USPIO probe was $84.16 \pm 13.00 \mathrm{~s}^{-1}$, compared with $18.82 \pm 4.42 \mathrm{~s}^{-1}$ for tumors receiving plain USPIO ("P $<0.05$ ). Similarily, R2* value increased significantly after injection of RGD-USPIO probe $\left(101.74 \pm 6.27 \mathrm{~s}^{-1}\right)$ compared with that of the plain USPIO group (24.46 $\left.\pm 4.45 \mathrm{~s}^{-1}\right)$ in A549 tumor A) T2* value of all the organs decreased after injection of RGD-USPIO or USPIO; however, there was no significant difference between the two probes B).

Abbreviation: RGD-USPIO, arginine-glycine-aspartic acid peptide conjugated ultra-small superparamagnetic iron oxide nanoparticles (RGD-USPIO).

study location and characterization of angiogenesis during metastasis in these organs.

\section{Conclusion}

Despite these problems, the results available have shown that the RGD-USPIO probe can specifically bind with endothelial cells of angiogenic blood vessels. Therefore, it is possible to delineate tumor angiogenesis and use the probe to monitor noninvasively change of angiogenesis during tumor therapy with the clinical 3.0T MR scanner. Although the targeting pattern of the probe is different in tumors with different $\alpha v \beta 3$ expressions, it is envisioned that MRI molecular imaging of target angiogenic blood vessels has a good future. ${ }^{28,29}$ First, it is a noninvasive monitoring method and would not affect tissue integrity. Second, it can detect the whole tumor and it is unnecessary to do tissue biopsy from one or more sites. Third, it is possible to monitor the tumor status or therapeutic effects in a quantitative real-time manner. Our future research will focus on seeking more specific target points and optimizing pharmacokinetic behaviors of the probe.

\section{Acknowledgments and disclosures}

We thank "Technical Innovation" Major Subject Program of Shanghai Committee of Science and Technology (No. 08DZ1900707, No. 06DZ19503) Shanghai Nanometer Technology Special Program (No. 0852nm03700), Special Program of Shanghai Committee of Science and Technology (No. 08JC1407500), Shanghai Natural Science Foundation (No. 08ZR1405200, 08ZR1411100) for the financial support.

The authors disclose no conflicts of interest.

\section{References}

1. Carmeliet P, Jain RK. Angiogenesis in cancer and other diseases. Nature. 2000;407(6801):249-257.

2. Vosseler S, Mirancea N, Bohlen P, Mueller MM, Fusenig NE. Angiogenesis inhibition by vascular endothelial growth factor receptor-2 blockade reduces stromal matrix metalloproteinase expression, normalizes stromal tissue, and reverts epithelial tumor phenotype in surface heterotransplants. Cancer Res. 2005;65(4):1294-1305.

3. Overmoyer B, Pingfu Fu, Charles H, et al. Inflammatory breast cancer as a model disease to study tumor angiogenesis: results of a phase IB trial of combination SU5416 and doxorubicin. Clin Cancer Res. 2007;13(19):5862-5868.

4. Hsu AR, Chen X. Advances in anatomic, functional, and molecular imaging of angiogenesis. J Nucl Med. 2008;49(4):511-514.

5. Brooks PC, Clark RA, Cheresh DA. Requirement of vascular integrin alpha v beta 3 for angiogenesis. Science. 1994;264(5158):569-571.

6. Dechantsreiter MA, Planker E, Mathä B, et al. N-Methylated cyclic RGD peptides as highly active and selective alpha(v)beta(3) integrin antagonists. J Med Chem. 1999;42(16):3033-3040.

7. Janssen ML, Oyen WJ, Dijkgraaf I, et al. Tumor targeting with radiolabeled alpha(v)beta(3) integrin binding peptides in a nude mouse model. Cancer Res. 2002;62(21):6146-6151.

8. Leong-Poi H, Christiansen J, Heppner P, et al. Assessment of endogenous and therapeutic arteriogenesis by contrast ultrasound molecular imaging of integrin expression. Circulation. 2005;111(24):3248-3254.

9. Beer AJ, Haubner R, Wolf I, et al. PET-based human dosimetry of $18 \mathrm{~F}$-galacto-RGD, a new radiotracer for imaging alpha $\mathrm{v}$ beta3 expression. J Nucl Med. 2006;47(5):763-769.

10. Lee H, Lee E, Kim do K, Jang NK, Jeong YY, Jon S. Antibiofouling polymer-coated superparamagnetic iron oxide nanoparticles as potential magnetic resonance contrast agents for in vivo cancer imaging. J Am Chem Soc. 2006;128(22):7383-7389.

11. Zhang C, Jugold Manfred, Woenne EC, et al. Specific targeting of tumor angiogenesis by RGD-conjugated ultrasmall superparamagnetic iron oxide particles using a clinical 1.5-T magnetic resonance scanner. Cancer Res. 2007;67(4):1555-1562.

12. Zhang C, Wängler B, Morgenstern B, et al. Silica- and alkoxysilanecoated ultrasmall superparamagnetic iron oxide particles: a promising tool to label cells for magnetic resonance imaging. Langmuir. 2007;23(3):1427-1434. 
13. Taupitz M, Schnorr J, Abramjuk C, et al. New generation of monomer-stabilized very small superparamagnetic iron oxide particles (VSOP) as contrast medium for MR angiography: preclinical results in rats and rabbits. J Magn Reson Imaging. 2000;12(6):905-911.

14. Kiessling F, Heilmann M, Vosseler S, et al. Dynamic T1-weighted monitoring of vascularization in human carcinoma heterotransplants by magnetic resonance imaging. Int J Cancer. 2003;104(1):113-120.

15. Geninatti Crich, Simonetta, Benedetta Bussolati, et al. Magnetic resonance visualization of tumor angiogenesis by targeting neural cell adhesion molecules with the highly sensitive gadolinium-loaded apoferritin probe. Cancer Res. 2006;66(18):9196-9201.

16. Peeters JM, Seppenwoolde JH, Bartels LW, Bakker CJ. Development and testing of passive tracking markers for different field strengths and tracking speeds. Phys Med Bio. 2006;51(6):127-137.

17. Soher BJ, Dale BM, Merkle EM. A review of MR physics: 3T versus 1.5T. Magn Reson Imaging Clin N Am. 2007;15(3):277-290.

18. Kohler N, Fryxell GE, Zhang M. A bifunctional poly(ethylene glycol) silane immobilized on metallic oxide-based nanoparticles for conjugation with cell targeting agents. J Am Chem Soc. 2004;126(23): 7206-7211.

19. Bruce IJ, Sen T. Surface modification of magnetic nanoparticles with alkoxysilanes and their application in magnetic bioseparations. Langmuir. 2005;21(15):7029-7035.

20. Sun EY, Josephson L, Kelly KA, Weissleder R. Development of nanoparticle libraries for biosensing. Bioconjug Chem. 2006;17(1):109-113.

21. Bogdanowich-Knipp SJ, Chakrabarti S, Williams TD, Dillman RK, Siahaan TJ. Solution stability of linear vs cyclic RGD peptides. J Pept Res. 1999;53(5):530-541.
22. Mulder WJ, Strijkers GJ, Habets JW, et al. MR molecular imaging and fluorescence microscopy for identification of activated tumor endothelium using a bimodal lipidic nanoparticle. FASEB J. 2005;19(14): 2008-2010.

23. Jackson, Alan, James PB, O'Connor, et al. Imaging tumor vascular heterogeneity and angiogenesis using dynamic contrast-enhanced magnetic resonance imaging. Clin Cancer Res. 2007;13(12):3449-3459.

24. Raatschen HJ, Fu Y, Sennino B, et al. Vascular permeability during antiangiogenesis treatment: MR imaging assay results as biomarker for subsequent tumor growth in rats. Radiology. 2008;247(2):391-399.

25. Achilefu S, Bloch S, Markiewicz MA, et al. Synergistic effects of light-emitting probes and peptides for targeting and monitoring integrin expression. Proc Natl Acad Sci U S A. 2005;102(22):7976-7981.

26. Tang $\mathrm{Y}$, Minjung $\mathrm{K}$, Daniel $\mathrm{C}$, et al. In vivo assessment of RASdependent maintenance of tumor angiogenesis by real-time magnetic resonance imaging. Cancer Res. 2005;65(18):8324-8330.

27. Raynal I, Prigent P, Peyramaure S, et al. Macrophage endocytosis of superparamagnetic iron oxide nanoparticles: mechanisms and comparison of ferumoxides and ferumoxtran-10. Invest Radiol. 2004; 39(1):56-63.

28. Winter PM, Caruthers SD, Kassner A, et al. Molecular imaging of angiogenesis in nascent $\mathrm{Vx}-2$ rabbit tumors using a novel alpha(nu)beta3targeted nanoparticle and 1.5 tesla magnetic resonance imaging. Cancer Res. 2003;63(18):5838-5843.

29. Oostendorp M, Kim D, Tilman M, et al. Quantitative molecular magnetic resonance imaging of tumor angiogenesis using cNGR-labeled paramagnetic quantum dots. Cancer Res. 2008;68(18):7676-7683.
International Journal of Nanomedicine

\section{Publish your work in this journal}

The International Journal of Nanomedicine is an international, peerreviewed journal focusing on the application of nanotechnology in diagnostics, therapeutics, and drug delivery systems throughout the biomedical field. This journal is indexed on PubMed Central,

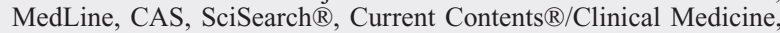

\section{Dovepress}

Journal Citation Reports/Science Edition, EMBase, Scopus and the Elsevier Bibliographic databases. The manuscript management system is completely online and includes a very quick and fair peer-review system, which is all easy to use. Visit http://www.dovepress.com/ testimonials.php to read real quotes from published authors. 